Objectives Social position and social mobility are associated with cancer incidence and mortality, yet little is known about their association with mediating factors such as occupational exposures to carcinogens. Our aim was to assess the association between the type of professional trajectory and multiple occupational exposure profiles.

Method Data were extracted from the Giscop93 study ( $\mathrm{n}=1$ 009), which is a cohort of cancer patients with (mainly) respiratory tumours. Job histories were reconstructed through interview, then a multi-disciplinary expert group examined the probability of occupational exposure to a list of 54 potentially carcinogenic agents. The typology of professional trajectories was built based on employment stability, employment continuity, job qualification trend, and multiple skills through Multiple Correspondence Analysis followed by Ascending Hierarchical Classification. Association with multiple-exposure profiles was then assessed through multiple logistic regression.

Results Men and women differed in terms of predominant job category over the lifecourse $(68,2 \%$ of blue-collar-workers among men, 57,3\% of employees among women, $\mathrm{p}<0.0001)$. Professional trajectories were grouped in four classes as "stable qualified, employee" $(21,3 \%)$, "stable manual, independent bluecollar-worker" (24,4\%), "stable tiring, no gain in qualification" $(30,5 \%)$, and "very unstable, precarious" $(23,8 \%)$. Among men, the last two categories were associated with exposure to at least five different occupational carcinogens $\left(\mathrm{OR}_{\text {stable_tiring/stable_quali- }}\right.$ fied $\left.=2,0[1,3 ; 3,1], \mathrm{OR}_{\text {very_unstable/stable_qualified }}=2,6[1,6 ; 4,2]\right)$. No such association was found among women.

Conclusions The association found between the type of professional trajectory and multiple occupational exposures among men should be replicated among people not suffering cancer. Forthcoming analysis will investigate the gendered differences observed.

\section{MENTAL HEALTH INEQUALITIES BY INFORMAL EMPLOYMENT AND GENDER IN CENTRAL AMERICA}

\begin{abstract}
1,2María López-Ruiz, 1,2 José M Martínez, 1,2Fernando G Benavides, 2,3 Vanessa Puig-Barrachina, ${ }^{2,4}$ Marianela Rojas, ${ }^{2,5}$ Lucía Artazcoz. ${ }^{1}$ CIBER Epidemiología Y Salud Pública (CIBERESP), Barcelona, Spain; '2Universitat Pompeu Fabra, Barcelona, Spain; ${ }^{3}$ Vrije Universiteit, Brussels, Belgium; ${ }^{4}$ Universidad Nacional de Costa Rica, Heredia, Costa Rica; ${ }^{5}$ Agència de Salut Pública de Barcelona, Barcelona, Spain
\end{abstract}

\subsection{6/oemed-2014-102362.267}

Objectives To analyse the relationship between mental health and non-agricultural informal employment in Central America; and to examine whether patterns of association differ by gender Method Cross-sectional study of 8904 non-agricultural workers ( $48 \%$ women) based on the I Central American Survey of Working Conditions and Health of 2011. Employment profiles were created combining formal and informal characteristics: labour relationship (permanent employees, temporary employees, selfemployed, employers), social security coverage (yes, no), type of contract for employees (written, oral or no contract), company size for employers $(\leq 5,>5$ workers). Using logistic regression models, odds ratios (OR) of poor mental health (measured by GHQ12 questionnaire) and 95\% confidence intervals (95\% CI) were calculated by sex, adjusting for country and age, with employment profiles as independent variable. The reference group was permanent employees covered by social security with a written contract.

Results Around 37\% of women and 34\% of men reported poor mental health. In both sexes all profiles without social security coverage were associated with poor mental health except for permanent employees. Temporary employees covered by social security were associated with poor mental health if they have oral or no contract for women and men. Covered permanent employees with oral or no contract among women (OR: 1.70, 95\% CI:1.12-2.59) and covered self-employed among men (OR: 1.59, 95\% CI:1.03-2.46) were associated with poor mental health.

Conclusions In Central America health inequalities by employment profiles exist, principally for not being covered by social security, or having an oral or no contract for employees (main characteristics of informal employment). Few gender inequalities have been found.

\section{THE PARTICIPATION FOR SOLID WASTE MANAGEMENT APPROPRIATE MODEL OF UNDERGRADUATE IN SRINAKHARINWIROT UNIVERSITY, THAILAND}

Anong Hansakul. Srinakharinwirot University, Bangkok, Thailand

\subsection{6/oemed-2014-102362.268}

Objectives The objective was to study participatory for solid waste management of undergraduate students Faculty of Physical Education Srinakarinwirot University Ongkarak.

Method Collect the data by the questionnaire developed interview used as a tool to collect employed quantitative data. The content validity was improved and adjusted by the suggestion of the experts.

Results The result revealed that: the sample were women $75.5 \%$, age between $18-22$ years old, age average 19.75 years old (S. D. $=1.047, \operatorname{Min}=18, \operatorname{Max}=22$ ), the bin condition, or storage of waste provided by the University have various stains $81.5 \%$, minor is not covered or close incompletely $56.8 \%$ and $36.1 \%$ damaged, broken or leaking the trash. The storage of waste by University provide cause of nuisance $88.7 \%$; almost of foul smell $92.5 \%$, minor is nuisance form animals and insects such as flies, mice, etc., $36.6 \%$ and the other (the leachate outflow / waste overflow flooded / gruesome) $4.2 \%$. The knowledge level about solid waste management almost moderate level 53.5\%, minor was high level $45.5 \%$ and low level $1.1 \%$. The attitude level about solid waste management almost moderate $65.8 \%$, minor were low level $18.2 \%$, and high level $16.0 \%$. The practice behaviour level about solid waste management almost moderate $72.8 \%$, minor were high level 15.2\% and low level 12.0\%.

Conclusions Undergraduate students have the knowledge, but not implemented for separate the garbage, and the correct type of waste, uncooperative for separate the garbage because of that embarrassment and there is not enough knowledge about solid waste management. The University do not have the campaign seriously.

\section{PROSTATE CANCER RISK AMONG FRENCH FARMERS IN THE AGRICAN COHORT}

${ }^{1,2}$ Clémentine Lemarchand, 1,2Séverine Tual, 1,2 Noémie Levêque-Morlais, ${ }^{1,2}$ Stéphanie Perrier, ${ }^{1,3}$ Anne-Valérie Guizard, ${ }^{4}$ Michel Velten, ${ }^{5}$ Emma Rigaud, ${ }^{6,7}$ Isabelle Baldi, ${ }^{1,2}$ Pierre Lebailly. 'INSERM, UMR1086 Cancers Et Préventions, F-14000, Caen, France; ${ }^{2}$ University of Caen Basse-Normandie, F-14000, Caen, France; ${ }^{3}$ Calvados General Tumor Registry, Centre François Baclesse, F-14000, Caen, France; ${ }^{4}$ Bas-Rhin Cancer Registry, Faculty of Medicine, University of Strasbourg, F-67085, Strasbourg, France; ${ }^{5}$ Mutualité Sociale Agricole, Caisse Centrale, F-93547, Bagnolet, France; ${ }^{6}$ INSERM, ISPED, Centre INSERM U897- Epidemiologie-Biostatistique, F-33000, Bordeaux, France; 'University of Bordeaux, ISPED, Laboratoire Santé Travail Environnement, F-33000, Bordeaux, France

10.1136/oemed-2014-102362.269 